\title{
Desenvolvimento local e agricultura familiar: o caso da produção de açúcar mascavo em Capanema - Paraná
}

Local development and family agriculture: the brown sugar production case in Capanema city- Paraná state in Brazil

Développement local et agriculture familiale: le cas de la production de sucre brun dans la ville de Capanema dans l'état du Paraná au Brésil

Desarrollo local y la agricultura familiar: el caso de la producción de azúcar marrón en la ciudad de Capanema - estado de Paraná en Brasil

\author{
Mariza Zeni de Castro Tomasetto* \\ Jandir Ferrera de Lima** \\ Pery Francisco Assis Shikida***
}

Recebido em 24/10/2008; revisado e aprovado em 29/11/2008; aceito em 17/12/2009

\begin{abstract}
Resumo: Esse estudo analisa, por meio de um estudo exploratório, o aporte dos produtos derivados da cana-deaçúcar no contexto do desenvolvimento local no município de Capanema - Paraná. Essa atividade se apresenta como opção para a produção da agricultura familiar ao criar alternativa de renda nas unidades agroindustriais, além de possibilitar a diversificação da produção. Os resultados mostram que a produção de açúcar mascavo e os demais produtos derivados da cana-de-açúcar, assim como os já tradicionais produtos da agricultura familiar, têm contribuído para aumentar a renda e melhorar as condições de vida dos agricultores e, conseqüentemente, vem impulsionando o desenvolvimento local, uma vez que tem incentivado o homem a permanecer no campo.

Palavras-chave : Economia agrícola. Agricultura familiar. Desenvolvimento local.

Abstract: This research analyzes the products input derived from the sugar cane through an exploratory study in the local development context of Capanema city in Paraná State. This activity is shown as an option for the family agriculture production as it raises an income alternative at agriculture and industry units, besides providing a production diversification. The results show that brown sugar production and all other sugar cane derived products, as well as the family agriculture traditional products, have contributed to increase the income and improve producers life conditions. As a consequence, it has stimulated the local development, once it has encouraged people to stay in the countryside.
\end{abstract}

Keywords: Agricultural economics. Family agriculture. Local development.

Résumé: Cette recherche analyse l'entrée de produits dérivés de la canne à sucre à l'aide d une étude exploratoire dans le contexte local de développement de la ville de Capanema dans l'état du Paraná. Cette activité est vue comme une option pour la production agricole familiale et comme une alternative de revenu aux unités d'agriculture et d'industrie, sans compter qu'elle fournit une opportunité de diversification de production. Les résultats prouvent que la production de sucre brun et toute autre canne à sucre et des produits dérivés, aussi bien que les autres produits traditionnels d'agriculture familiale ont contribué à augmenter le revenu et améliorer la qualité de vie des producteurs. Par conséquent, elle a stimulé le développement local, incitant les personnes à demeurer dans la campagne.

Mots-clés: Économie agricole. Agriculture de famille. Développement local.

Resumen: Esta investigación analiza, a través de un estudio exploratorio, la producción de azúcar marrón en el contexto de desarrollo local de la ciudad de Capanema en el Estado de Paraná en Brasil. Esta actividad se muestra como una opción para la producción en el contexto de la agricultura familiar, ya que plantea una alternativa de ingresos para las unidades familiares, además de proporcionar una diversificación de la producción agrícola. Los resultados de la investigación muestran que la producción de azúcar marrón y todos los demás derivados de la caña de azúcar, así como los productos de la agricultura tradicional, han contribuido a aumentar los ingresos y los productores de mejorar las condiciones de vida de los pequeños agricultores de la ciudad de Capanema. Como consecuencia de ello, se ha estimulado el desarrollo local, una vez que ha alentado a la gente a permanecer en el campo.

Palabras clave : Economía agrícola. Agricultura familiar. Desarrollo local.

\footnotetext{
* Administradora. Mestranda do Programa de Pós-Graduação em Desenvolvimento Regional e Agronegócio, na Universidade Estadual do Oeste do Paraná (UNIOESTE/Toledo-PR). E-mail: mzcastro@hotmail.com ** Doutor em Desenvolvimento Regional (Ph.D.) pela Université du Québec (UQAC). Professor Adjunto do Programa de Pós-Graduação em Desenvolvimento Regional e Agronegócio da UNIOESTE/Toledo. Pesquisador do CNPq e do Grupo de Pesquisas em Desenvolvimento Regional e Agronegócio (GEPEC). E-mail: jandir@unioeste.br *** Doutor em Economia Aplicada (ESALQ/USP). Professor Associado do Programa de Pós-Graduação em Desenvolvimento Regional e Agronegócio da UNIOESTE/Toledo. Pesquisador do CNPq e do Grupo de Pesquisas em Desenvolvimento Regional e Agronegócio (GEPEC) da UNIOESTE/Toledo. E-mail: pfashiki@unioeste.br
} 


\section{Introdução}

Em meados do século XX teve início o programa chamado "Revolução Verde", resultando em grande impacto social, na medida em que ajudou a diminuir a fome no mundo. Entretanto, a sustentabilidade do programa foi questionada por fazer elevado uso de fertilizantes e agrotóxicos, desencadeando danos ao meio ambiente. Desde então, o segmento rural - no que tange a sua estrutura produtiva - tem buscado alternativas de produção que contemplem, ao mesmo tempo, os âmbitos ecológicos e econômicos (CUNHA e LEMOS, 1997).

A partir dos anos 1990, a agricultura familiar, como forma de diversificação da produção, vem se desenvolvendo em todos os pontos do mundo e tem como característica a predominância da mão-de-obra e gerenciamento por membros da família. Ao contrário da agricultura convencional, a agricultura familiar busca equilibrar o uso dos recursos naturais atuando ativamente no processo de transição para uma agricultura sustentável. De acordo com Schneider (2003, p.117), em relação ao debate sobre a agricultura familiar, as formas familiares de organização do trabalho e da produção não estão mais restritas somente ao setor agrícola e ao espaço rural, existem outras atividades - daí a questão do debate em torno da pluriatividade - na qual se pode observar uma estratégia de reprodução social e econômica das famílias rurais.

No município de Capanema - Paraná, a cadeia produtiva da cana-de-açúcar orgânica, assim como a produção, transformação e a comercialização de açúcar mascavo e outros derivados da cana-de-açúcar, começou a se definir com a implantação das agroindústrias de agricultores familiares como estratégia para o desenvolvimento rural local.

Por isso, este trabalho tem o propósito de analisar, por meio de um estudo exploratório, o aporte dos produtos derivados da cana-de-açúcar no contexto do desenvolvimento local no município de Capanema Paraná, com o intuito de contribuir para a discussão do desenvolvimento rural local e, ao mesmo tempo, divulgar experiências passíveis de serem adotadas em outros espaços.
O foco da análise é a produção de açúcar mascavo, que, segundo Departamento de Estudos Sócio-econômicos Rurais - DESER (2005), tem na cana-de-açúcar a sua base de produção, sendo grande parte desse produto proveniente da agricultura familiar. Portanto, buscou-se responder à seguinte questão: a produção do açúcar mascavo e os demais produtos derivados da cana-de-açúcar contribuem com o desenvolvimento local do município e mantêm a família no campo?

Como esse estudo é exploratório, envolveu pesquisa bibliográfica e documental sobre agricultura familiar, desenvolvimento local e agroindústria familiar. Segundo Gil (1999), as pesquisas exploratórias têm como objetivo principal desenvolver, esclarecer e modificar conceitos e idéias, tendo em vista a formulação de problemas ou hipóteses. Os dados secundários foram coletados em órgãos governamentais e não-governamentais, como da Secretaria Municipal de Agricultura do Município de Capanema, Sistema de Cooperativas da Agricultura Familiar (COOPAFI) e Empresa de Assistência Técnica e Extensão Rural (EMATER), entre outros.

Os dados primários foram obtidos por meio da pesquisa de campo e envolveu visitas em quatro das dez agroindústrias familiares localizadas em Capanema, que tem como alternativa de renda a produção de açúcar mascavo, entre outros produtos derivados da cana-de-açúcar, mais uma agroindústria que produz bolacha e rapadura, e também com entrevistas feitas aos agricultores responsáveis pelas unidades pesquisadas, com um roteiro previamente elaborado e abordando os aspectos necessários para atender ao objetivo do estudo.

Além desta introdução, este estudo constitui-se de uma breve caracterização do território estudado, algumas considerações sobre agricultura familiar, desenvolvimento local, agroindústrias familiares, produção de açúcar mascavo e principais agentes dinamizadores do processo do desenvolvimento local (seção 2). Os resultados e discussões (seção 3) e as conclusões do estudo (seção 4) completam este trabalho. 


\section{Caracterização do território do estudo}

Segundo Instituto Paranaense de Desenvolvimento Econômico e Social IPARDES (2004), a Região Sudoeste do Paraná, com uma área de $11.687 \mathrm{~km}^{2}$, possui 37 municípios e do total das propriedades, $87 \%$ são familiares e destas, $94 \%$ possuem áreas inferiores a 50 ha. As condições de uso do solo, do processo migratório e outros fatores de ordem social e econômica fazem com que predominam no Sudoeste do Paraná micro e pequenas propriedades rurais, proporcionando a diversificação de culturas e, por iniciativa do setor público, órgãos/entidades de assistência técnica e empresas do setor privado, deu-se ênfase na agricultura familiar, o que tem contribuído para manter o homem no campo com certa qualidade de vida (MINISTÉRIO DO TRABALHO E EMPREGO - MTE, 2004).

O território estudado - Capanema corresponde à mesorregião geográfica Sudoeste Paranaense, microrregião geográfica Capanema, localizada na Região Sul do Brasil. De acordo com Instituto Brasileiro de Geografia e Estatística - IBGE (2007), o município de Capanema conta com uma população de 18.103 habitantes e está situado na divisa com a Argentina e o Parque Nacional do Iguaçu, conforme figura 1.

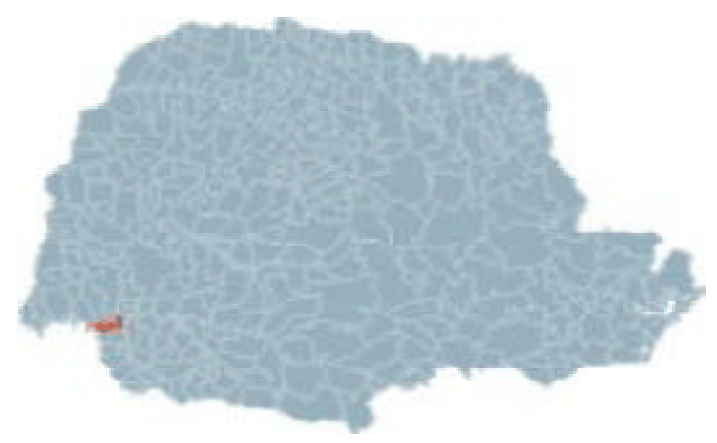

Figura 1 - Localização do Município de Capanema - PR

Fonte: IPARDES (2008)

Segundo a Prefeitura Municipal de Capanema (2007), como a economia do município é essencialmente agrícola e a cana-de-açúcar se destaca como uma das principais atividades agrícolas do município, há um esforço local para oferecer novas alternativas de produção para manter o homem na terra, já que tem como característica a ocupação do espaço pela agricultura familiar e, conseqüentemente, seus produtos apresentam característica de produtos orgânicos oriundos dessa atividade econômica, em especial, a produção de açúcar mascavo.

\subsection{Agricultura familiar}

Segundo Lamarche (1993), a família, o trabalho e a propriedade são os elementos centrais da agricultura familiar. Essas são algumas das características das unidades de produção agrícola que utilizam principalmente a mão-de-obra familiar. Além disso, de acordo com Veiga (1996), as vantagens da agricultura familiar vão além da diversificação da produção, pois apresenta um perfil essencialmente distributivo e sustentável, bem como o fortalecimento dos agricultores.

Para Abramovay (2000), um projeto de desenvolvimento local sustentável para a agricultura familiar deve observar as especificidades regionais e adaptar culturas com maior potencial de produção, visto que a maior parte da produção agrícola mundial tem origem nos estabelecimentos familiares. Isso mostra a importância da formação de identidades e da diferenciação das regiões ao pensar em desenvolvimento local, enfatizando as preocupações com os aspectos sociais.

Deve-se ressaltar, ainda, que o potencial do desenvolvimento sustentável é medido pela sua capacidade de satisfazer as necessidades humanas de maneira a integrar os aspetos sociais, ambientais e econômicos. Nesse sentido, é extremamente importante que haja um equilíbrio entre esses pontos em relação à agricultura familiar de produção orgânica, visando ao aspecto econômico garantir renda ao produtor rural. Do ponto de vista social, por ser um sistema pouco mecanizado, demanda maior número de mão-deobra e promove a inclusão social. Além disso, com as acirradas discussões sobre meio ambiente, na produção orgânica, os impactos são limitados (FERRERA DE LIMA, 2002).

A organização e a participação dos agricultores familiares no processo de desenvolvimento local, buscando distribuição de renda e equiidade social e ao mesmo tempo promovendo uma relação mais equilibrada 
com a natureza, corroboram as palavras de Santos e Silveira (2005, p. 118), de que "inovações técnicas e organizacionais na agricultura concorrem para criar um novo uso do tempo e um novo uso da terra".

\subsection{Desenvolvimento local: elementos teóricos}

Segundo o Institut de Formation em Développement Communautaire - IFDEC (1992), o desenvolvimento local pode ser definido como uma estratégia de intervenção socioeconômica por meio da qual se incentiva o empreendedorismo dos representantes locais do setor privado, público ou social, a valorizar os recursos humanos, técnicos e financeiros de uma sociedade, com o objetivo principal de crescimento da economia local.

A abordagem do desenvolvimento local ganhou destaque nas últimas décadas frente aos desafios impostos pela nova dinâmica econômica, ou seja, reestruturação produtiva, em que propostas administradas pelos governos locais e regionais procuram assegurar o desenvolvimento econômico de cidades e regiões. As experiências de desenvolvimento local indicam que o caminho a seguir passa pela formulação e aplicação de uma estratégia de desenvolvimento, operacionalizada com base em ações que busquem realizar os objetivos de produtividade e competitividade, para estimular o desenvolvimento local (BARQUERO, 2001).

Martins (2002) complementa que a característica do desenvolvimento local é a maneira de atribuir e garantir à comunidade a função de agente em prol do desenvolvimento ao invés de simplesmente beneficiária.

Enfim, pode-se entender o desenvolvimento local como uma resposta, num contexto de globalização e reestruturação produtiva, às vicissitudes de desenvolvimento. $\mathrm{O}$ termo Local alcançou uma importância fundamental no contexto econômico, graças às oportunidades decorrentes desse novo ambiente produtivo. A qualidade de vida também é essencial no desenvolvimento local como representação da sustentabilidade de uma economia local (MARTINELLI e JOYAL, 2004; SHIKIDA et al., 2008).

\subsection{As agroindústrias familiares e o desen-} volvimento local

Mior (2005) define a agroindústria familiar rural como uma forma de organização e transformação da produção familiar, com vistas a agregar valor ao produto na hora da comercialização e, de acordo com Prezotto (2000), a agroindústria familiar é uma ferramenta capaz de impulsionar o desenvolvimento local sustentável por meio da geração direta e indireta de novos postos de trabalho e renda para os agricultores familiares, melhorando sua qualidade de vida.

Além disso, as agroindústrias familiares têm desempenhado importante papel no desenvolvimento do país e com grande importância sócio-econômica, principalmente na geração de empregos no campo, distribuindo melhor a renda e melhorando a qualidade de vida dos agricultores, diminuindo assim, a migração campo-cidade. Comumente, as tecnologias empregadas são as tradicionais ou artesanais e seus produtos são ligados à cultura local (LOUREZANI e SILVA, 2000).

A partir da década de 1990, desencadearam-se na Região Sudoeste Paranaense iniciativas voltadas à constituição de agroindústrias familiares rurais como diversificação da economia agrícola e promoção do desenvolvimento local. O município de Capanema, além de desenvolver a agricultura familiar e a produção de alimentos orgânicos, incentivando o associativismo e a formação de agroindústrias, conta com o apoio do Parque Nacional do Iguaçu, pois vem ao encontro das atividades indicadas para a área de entorno de uma unidade de conservação por ser menos agressiva ao meio ambiente (MINISTÉRIO DO MEIO AMBIENTE - MMA, 2008).

Nesse contexto, as agroindústrias em Capanema foram projetadas e construídas com o objetivo de facilitar o trabalho de transformação, aumentar a produtividade e melhorar a qualidade do produto final, iniciativa que visa transformar o município em pólo de produção de açúcar mascavo e outros produtos derivados da cana-de-açúcar. 
1.4 Produção de açúcar mascavo e agentes dinamizadores do processo de desenvolvimento local em Capanema Paraná

Entre 1970 e 1990, a produção de cana e a fabricação de açúcar mascavo foram deixadas de lado pelos agricultores familiares, mas, em 1995, no Sudoeste do Paraná, a Coordenação Regional de Associações iniciou o processo de comercialização de açúcar mascavo e assim esse produto se tornou uma importante atividade econômica para um número cada vez maior de famílias e associações dessa região (COORDENAÇÃO REGIONAL DE ASSOCIAÇÕES - CRAPA, 1999).

Ainda hoje os incentivos à produção de derivados da cana-de-açúcar se justificam pela tradição que Capanema tem nesse segmento, fazendo com que essa atividade procure se desenvolver e se organizar. O município é grande exportador de produtos orgânicos, possui ainda algumas áreas voltadas para o turismo ecológico e vem despontando no cenário nacional como um município de destaque no Sudoeste Paranaense.

Nesse cenário, destaca-se a união de forças e recursos em novos arranjos com o objetivo de criar empregos e impulsionar o desenvolvimento local, como no caso das agroindústrias de açúcar mascavo.

Segundo Ferrera de Lima et al. (2005), as agroindústrias de açúcar mascavo se desenvolveram em Capanema e nos municípios da fronteira Sudoeste para diminuir problemas como desemprego e êxodo rural, além de impulsionar o desenvolvimento local.

Isso ocorre porque os produtores recebem assistência de diversas entidades governamentais e não-governamentais e essa parceria se tornou indispensável para proporcionar aos produtores maior competitividade na comercialização dos produtos.

Assim, o Governo do Estado participa dessa assistência aos agricultores, por meio da Secretaria de Estado da Agricultura e Abastecimento - SEAB; Instituto Paranaense de Assistência Técnica e Extensão Rural INSTITUTO EMATER (com 91 técnicos atuando em agricultura orgânica). Outros órgãos que atuam na agricultura orgânica no Sudoeste do Estado são as Associação de
Estudos, Orientação e Assistência Rural ASSESOAR; Centro de Tecnologias Alternativas- CETAP; Centro Paranaense de Apoio ao Pequeno Agricultor-CAPA; Sistema de Cooperativas da Agricultura FamiliarCOOPAFI; Coordenação Regional de Associação de Pequenos Agricultores-CRAPA; Organizações não Governamentais-ONGs; Universidades; Prefeituras Municipais; Associações de Produtores Orgânicos; Associações de Consumidores e Empresas de Processamento e Comercialização (EMATER, 2008). As Organizações e Associações citadas são algumas das que fornecem assistência técnica e apoio ao projeto orgânico de grãos e açúcar mascavo do Sudoeste, fomentando o desenvolvimento da agricultura, o desenvolvimento local sustentável e a promoção da cidadania e da qualidade de vida dos produtores rurais.

Essas ações fazem parte do processo de diversificação da pequena propriedade e agregação de valor de produto primário, beneficiando as agroindústrias rurais de Capanema na produção e comercialização dos produtos derivados da cana-de-açúcar.

Sobre a produção de açúcar mascavo e agentes dinamizadores do processo de desenvolvimento local em Capanema, vale destacar também o estudo feito por Perondi e Kiyota (2002, p.366), que apontou para a importância, neste município, da Feira do Melado. Ademais, "existem várias agroindústrias de açúcar mascavo, que concorrem no preço, por isto estas famílias buscam um novo espaço no mercado com as bolachas; tal segmento de mercado foi conquistado pela rápida percepção e reorientação da produção, reorganizando o trabalho dos homens e mulheres".

\section{Resultados e discussões}

Nas agroindústrias pesquisadas, a média de residentes na propriedade é de quatro pessoas, porém a média de trabalhadores familiares nas agroindústrias é de duas pessoas. Normalmente os filhos exercem atividades não-agrícolas fora da unidade de produção familiar.

Em Capanema estão instaladas doze agroindústrias familiares e dez delas produzem açúcar mascavo e demais produtos de- 
rivados da cana-de-açúcar, entre outros produtos tradicionais da agricultura familiar. Duas agroindústrias produzem outros derivados da cana, porém, já em vias de iniciar a produção de açúcar mascavo. A tabela 1 mostra a produção de açúcar mascavo e produtos derivados da cana-de-açúcar em Capanema na safra 2007 e as respectivas agroindústrias.

Tabela 1 - Agroindústrias e produção de açúcar mascavo e produtos derivados da cana-deaçúcar em Capanema, PR - 2007

\begin{tabular}{lrrrrr}
\hline \multicolumn{1}{c}{ Agroindústria } & $\begin{array}{c}\text { Açúcar } \\
\text { Mascavo kg }\end{array}$ & $\begin{array}{c}\text { Melado } \\
\text { kg }\end{array}$ & $\begin{array}{c}\text { Bolacha de } \\
\text { Melado kg }\end{array}$ & Rapadura kg & $\begin{array}{c}\text { Cachaça } \\
\text { litros } \\
\text { Pingo de Mel }\end{array}$ \\
$\begin{array}{l}\text { Pé de Cana } \\
\text { Nova Sul }\end{array}$ & 10.000 & 3.000 & & & 15.000 \\
Terra Boa & 5.000 & 3.000 & & & \\
Piamolim & & 3.000 & & & \\
Manguaba & 4.500 & 6.000 & 1.200 & 2.640 & \\
Pavão & 6.000 & 6.000 & 4.320 & 2.775 & \\
Loli & 10.000 & & & & \\
Nascer do Sol & & & 3.800 & & \\
APALGE & 11.000 & & & & \\
Pinheiro(01) & 20.000 & 30.000 & 2.000 & 900 & \\
Pinheiro(02) & 30.000 & 20.000 & 1.000 & & $\mathbf{1 5 . 0 0 0}$ \\
\hline Total & $\mathbf{1 4 7 . 5 0 0}$ & $\mathbf{7 1 . 0 0 0}$ & $\mathbf{1 4 . 3 2 0}$ & $\mathbf{9 . 3 1 5}$ &
\end{tabular}

Fonte: Dados da pesquisa (2008)

De acordo com a tabela 1, em 2007, as agroindústrias localizadas em Capanema totalizaram uma produção de $147.500 \mathrm{~kg}$ de açúcar mascavo, $71.000 \mathrm{~kg}$ de melado, $14.320 \mathrm{~kg}$ de bolachas de melado, $9.315 \mathrm{~kg}$ de rapadura e 15.000 litros de cachaça. Na totalidade, essas agroindústrias são predominantemente familiares, administradas pela família e associadas à cooperativa. Todos são pequenos produtores e o plantio é feito manualmente.

Uma das unidades agroindustriais familiares pesquisadas - Agroindústria PIAMOLIN, possui uma área de 6,05 ha, é administrada pelo proprietário da terra e quatro pessoas da família estão envolvidas nas atividades de produção dos produtos derivados de cana-de-açúcar. Segundo o Sr. Ivo Piamolin, a agroindústria foi instalada em 2000 e, antes disso, as atividades desenvolvidas estavam relacionadas com a produção de leite, fumo, soja e milho. Atualmente, o açúcar mascavo é seu principal produto, seguido dos outros derivados da cana. Para essa família, após a implantação da agroindústria, os resultados foram positivos, pois construíram uma casa melhor, compraram um carro e conseguiram terminar de pagar o empréstimo feito para a construção do Galpão de fumo, além de ter de volta um dos filhos que trabalhava na cidade. Segundo o Sr. Ivo, os produtos são vendidos no mercado orgânico do município, a família participa da tradicional Feira do Melado que acontece a cada dois anos no município, vende nas cidades vizinhas e para os turistas que visitam a agroindústria por meio do convênio entre as agroindústrias e Prefeitura Municipal, o que ajudou bastante na comercialização dos produtos. Outro fato que tem contribuído com essa prática é o uso do selo Natural do Campo, que identifica os produtos da agricultura familiar elaborados no município. Os produtos mais vendidos são as bolachas e o melado, ele ressaltou ainda que a EMATER e a Prefeitura atuam na orientação e organização da produção. Mesmo assim, segundo o agricultor, a forma de comercialização ainda não atingiu níveis satisfatórios. A renda obtida com o açúcar mascavo fica acima de $\mathrm{R} \$ 1.000,00 /$ mensais.

Agroindústria TERRA BOA - De propriedade do Sr. Dalmir Trento, com 7,26 ha de terra, iniciou as atividades em 2000, com recursos próprios e apoio da EMATER. Administrada pelo proprietário, emprega quatro pessoas da família, mais dois trabalhadores temporários. Sua produção está volta- 
da principalmente para bolachas e rapaduras e está com projeto para iniciar a produção de açúcar mascavo. Com a renda da agroindústria, construiu casa, espaço para comercializar os produtos na propriedade (onde trabalha uma das filhas) e também comprou um carro. Essa agroindústria também faz parte do turismo rural e ele entrega produtos no mercado orgânico do município e participa da Feira do Melado. A renda dessa família está situada entre R\$1.000,00 e R\$ 1.500 mensais.

Agroindústria PÉ DE CANA - Essa agroindústria produz açúcar mascavo e melado e possui uma área de 6,05 ha. Suas atividades se iniciaram em 2002, com duas famílias associadas. No entanto, devido a divergências de idéias, hoje a agroindústria é administrada por uma só família, na qual trabalham o casal de agricultores. Um dos filhos, por opção, trabalha na cidade durante meio período e no outro ajuda a família. Antes de começar a produção de cana-deaçúcar e a agroindustrialização, o proprietário dessa agroindústria trabalhava na cidade. Nesse caso, a agroindústria possibilitou trazê-lo de volta para o meio rural, o que não aconteceu com os outros dois membros da família que preferem trabalhar na cidade. Segundo o Sr. Davi Agnes, a bolacha é o produto mais vendido, ainda assim para a família a produção de açúcar mascavo é economicamente viável, pois gera uma renda média de $\mathrm{R} \$ 1.000,00$ / mês e estar associado à cooperativa tem apresentado vantagens somente na hora da comercialização, mas já existe uma possibilidade de futuramente produzir também para exportação.

Agroindústria MANGUABA - Segundo a Sra. Erani Morgenstern - uma das associadas - a agroindústria iniciou as atividades em 1998, com sete famílias integradas, sendo que a proposta inicial e que segue até hoje foi de que só os casais trabalhariam na agroindústria, os filhos e demais membros da família deveriam desenvolver atividades alternativas, ou seja, trabalhar em outras atividades agrícolas ou não-agrícolas. Assim, iniciaram a produção de açúcar mascavo e melado e depois a produção de bolachas, sendo esse produto o carro-chefe da agroindústria. Para esses associados, a produção de derivados da cana-de-açúcar contribuiu sim para mantê-los no campo e se não fosse pela agroindústria todos já teriam migrado para a cidade. Antes dessas atividades, as famílias plantavam fumo e criavam gado de leite. Essa agroindústria trabalha em regime de empresa, a diretoria muda a cada ano e cada família produz cana, trabalhando e dividindo os lucros em igual medida. Se alguém falta ou chega atrasado ao trabalho é descontado no final do mês da sua parte a receber. Nessa agroindústria, as mulheres cuidam da produção de bolachas e contam com uma cozinha totalmente industrial adquirida com resultados financeiros da própria agroindústria, e os homens cuidam da produção de açúcar mascavo. A renda das famílias gira em torno de $\mathrm{R} \$ 1.000,00$ a $\mathrm{R} \$ 1.500,00$ mensais. Hoje, a agroindústria conta com apenas três famílias associadas, pois motivos diferentes levaram as famílias a desistirem da agroindústria. Quanto aos produtos, estes são comercializados no mercado local, inclusive para merenda escolar. Essa agroindústria é associada à COOPAFI - Cooperativa de Comercialização da Agricultura Familiar Integrada e contam com apoio da EMATER e Prefeitura Municipal, além de fazer parte do roteiro de turismo vendendo seus produtos na própria unidade produtiva.

Agroindústria PINGO DE MEL - Em 1999, a família Hass e mais sete famílias instigadas com a possibilidade de organizar uma agroindústria começaram a produzir açúcar mascavo e demais produtos derivados da cana-de-açúcar. Porém, atualmente, só a família proprietária da terra onde está inserida a agroindústria continua na unidade agroindustrial, pois as demais famílias desistiram por não se adaptarem e também pela dificuldade de conciliar os cuidados com as outras culturas. A renda, inicialmente, só era suficiente para pagar o financiamento, o que levou as famílias a abandonarem o projeto. Os principais problemas enfrentados pelas famílias no início das atividades, além da renda, foram a convivência entre os membros e divergências no gerenciamento da agroindústria. As famílias que desistiram dessa agroindústria continuam no campo cuidando das suas propriedades e das atividades agrícolas.

A família que continuou com a agroindústria é composta por quatro pessoas que 
anteriormente plantavam soja, feijão e milho. Depois da agroindústria, cultivam apenas cana-de-açúcar e o principal produto comercializado é o açúcar mascavo. Há quatro anos iniciaram a produção de cachaça e a perspectiva é de gradualmente focar somente nesse produto, pois a cooperativa de cachaça do Sudoeste iniciou negociação para exportar. Essa família enfatiza que suas condições econômicas mudaram para melhor depois da agroindústria, mesmo que o trabalho tenha aumentado. Das cinco agroindústrias visitadas, essa é a única que contrata em média de dois a três trabalhadores temporários na época de cortar a cana-de-açúcar. A área da propriedade é de 4,84 ha e tem parceiros que fornecem cana-de-açúcar para a agroindustrialização dos produtos derivados da cana. A produção de açúcar mascavo é a maior geradora de renda da família, que fica entre $\mathrm{R} \$ 1.000,00$ e $\mathrm{R} \$ 1.500,00$.

A comercialização da produção dessa agroindústria é feita pelo proprietário na região Sudoeste e no Estado de Santa Catarina, além disso, também é vendida para a cooperativa e ainda para o programa Fome Zero.

No geral, verificou-se que a produção de bolachas é feita normalmente pelas mulheres das famílias, em locais distintos da produção de açúcar mascavo e melado, trabalho feito pelos homens, por exigir mais força braçal, pois segue as seguintes etapas: colheita da cana de açúcar, moagem, fervura, batedor, peneira e embalagem. Ressalte-se que a produção de bolachas - que é responsável por boa parte da renda das famílias - não é produzida em sua totalidade com açúcar mascavo, e sim de maneira tradicional.

\section{Conclusão}

A diversificação da agricultura familiar para um desenvolvimento local sustentável aponta para a importância das agroindústrias no sentido de agregar valor aos produtos, gerar trabalho e renda para os produtores, além de viabilizar a comercialização dos produtos derivados da cana-de-açúcar, a exemplo da Feira do Melado, que já é evento tradicional em Capanema (Paraná).

O município já se tornou tradicional na produção de açúcar mascavo e os agentes que atuam nas estratégias, na valorização e na comercialização dos produtos derivados da cana-de-açúcar se empenham em dar suporte para que os agricultores familiares transformem os produtos artesanais em agroindustriais, mantendo o estilo e a receita tradicionais, para então, expor os produtos em nível local, regional e até mesmo exportar derivados de cana-de-açúcar, com destaque para o açúcar mascavo, que é um dos principais produtos elaborados nas agroindústrias familiares do município.

Um aspecto verificado no decorrer da pesquisa e que tem influenciado na promoção do desenvolvimento local em Capanema é o turismo rural. Essa nova tendência turística que os atores sociais do território estudado buscam desenvolver destaca ainda mais a atividade econômica natural do local. O turismo rural, abrangendo as unidades produtivas da agricultura familiar, assume considerável papel na divulgação dos produtos locais.

Nota-se que as agroindústrias familiares que estão mais próximas da cidade são mais independentes e se beneficiam mais das alternativas de comercialização. Quanto às associações, de acordo com os agricultores pesquisados, elas são eficientes na organização da produção, mas em relação à comercialização, ainda não se mostram totalmente satisfatórias.

Outra particularidade se refere ao fato de que nas agroindústrias normalmente são os casais que trabalham, o que já é pré-determinado no início das atividades e, dessa forma, os filhos vão trabalhar na cidade, mesmo que alguns continuem residindo na área rural. Em relação ao sistema de trabalho, quando há participação de mais de uma família nas unidades agroindustriais, cada família deve contribuir com o mesmo número de pessoas para trabalhar, assim como o fornecimento da cana-de-açúcar. Isso tem feito com que o espírito de cooperação e associativismo venha, ao longo do tempo, diminuindo, pelo fato de que em determinadas situações existem divergências administrativas.

Nas agroindústrias visitadas é unânime entre os agricultores que a produção de açúcar mascavo e outros produtos derivados da cana-de-açúcar contribuem para a melhoria das condições de vida das suas famílias, 
embora não vivam somente com a renda da produção de açúcar mascavo. A maioria tem outras atividades produtivas para complementar a renda, como a criação de algumas cabeças de gado leiteiro. Ainda assim, a renda dos agricultores familiares pesquisados situa-se dentro da renda média anual das unidades familiares, que segundo EMATER (2006), é de $\mathrm{R} \$ 10.000,00$ embora algumas tenham renda acima desse valor. Os dados mostram que para os agricultores familiares das unidades pesquisadas o açúcar mascavo - como único e exclusivo produto dessa atividade - não é economicamente viável, e sim a produção dos derivados da cana-de-açúcar de maneira geral.

Apesar da desistência de algumas famílias que buscaram aposentadoria e migraram da área rural para a cidade seguindo seus filhos ou decidiram exercer outras atividades agrícolas, os agricultores pesquisados enfatizam que após a implantação da agroindústria e com a produção de açúcar mascavo e demais produtos derivados da cana-de-açúcar, conseguiram melhorar suas casas, comprar carros, investir na infra-estrutura e aumentar a capacidade produtiva.

Nesse sentido, pode-se dizer que a cana-de-açúcar tem contribuído como alternativa de produção, assim como o açúcar mascavo, porém, não é esse produto o principal elemento que tem mantido o homem no campo e que desencadeia desenvolvimento local, mas está entre os que contribuem com a renda com os demais produtos derivados da cana.

Enfim, essas atividades de produção relacionadas com a cana-de-açúcar gradativamente vêm dando condições para que essas famílias continuem na área rural. No entanto, ainda há muito a fazer principalmente em relação à comercialização, para que realmente se possa dizer que a produção de açúcar mascavo e demais produtos derivados da cana-de-açúcar contribuem efetivamente para o desenvolvimento local e a permanência do homem no campo.

\section{Referências}

ABRAMOVAY, R. O capital social dos territórios: repensando o desenvolvimento rural. Revista de Economia Aplicada, São Paulo: FIPE, v. 4, n. 2, p. 379-397, jan./jun. 2000.

BARQUERO, A. Desenvolvimento endógeno em tempos de globalização. Porto Alegre: FEE, 2001. 280 p.

CRAPA - Coordenação Regional de Associações. Cambota, ano 27, n. 244, mar. 1999. Dispo-nível em: <http:/ / sistema.assesoar.org.br/arquivos / ART000221.htm>. Acesso em: 3 maio 2008.

CUNHA, A.R.A. de A.; LEMOS, M.B. Segurança alimentar sob o prisma das políticas urbanas de abastecimento. Texto para discussão, CEDEPLAR/FACE/ UFMG, n. 113, 26p, 1997.

DESER - Departamento de Estudos Socioeconômicos Rurais. A conjuntura da produção de cana-de-açúcar no Brasil e a dinâmica das exportações de açúcar no mercado mundial. 2005. Disponível em: <http:// www.mda.gov.br/saf/arquivos/estudo_cana-deacucar.pdf>. Acesso em: 19 abr. 2008.

EMATER - Instituto Paranaense de Assistência Técnica e Extensão Rural. Processo agricultura orgânica. Disponível em: <http://www.emater.pr.gov.br/ emater.php? emater $=2 \&$ mid $=87>$. Acesso em: 18 maio 2008.

A agricultura do Paraná. 2006. Disponível em: <http://www.senge-pr.org.br/eventos/vinho/ UVA\%20RUSTICA \%20-\%20SINTESE\%20FINAL.pdf>. Acesso em: 19 ago. 2008.

FERRERA DE LIMA, J. Les limites et le potentiel du développement durable. Revista Interfaces, Brasil/ Canadá., v. 1, n. 2, p.187-196, 2002.

FERRERA DE LIMA, J.; ALVES, L.R.; KARPINSKI, C.; PIACENTI, C.A.; PIFFER, M. A região de Salto Caxias no sudoeste paranaense: elementos para uma política de desenvolvimento econômico microrregional. Revista Paranaense de Desenvolvimento, Curitiba, n. 108, p. 87-111, 2005.

GIL, A.C. Métodos e técnicas de pesquisas. 3. ed. São Paulo: Atlas,1999.

IBGE - Instituto Brasileiro de Geografia e Estatística. Cidades, 2007. Disponível em: <http:// www.ibge.gov.br/cidadesat/default.php>. Acesso em: 15 maio 2008

IFDEC - Institut de Formation em Développement Communautaire. Le développement économique communautaire et les CDEC montréalaises. Colloque d'orientation, Montréal, 1992.

IPARDES - Instituto Paranaense de Desenvolvimento Econômico e Social. Leituras regionais: mesorregiões geográficas do Paraná. Curitiba: IPARDES, 2004.

. O mercado de orgânicos no Paraná: caracterização e tendências. Curitiba: IPARDES, 2007. Disponível em: $<$ httpwww.ipardes.gov.brwebisis.docsmercado_organicos_2007.pdf>. Acesso em: 20 jun. 2008.

Caderno estatístico do Município de Capanema. 2008. Disponível em: <http://www.ipardes.gov.br/cadernos/ Montapdf.php?Municipio=85760>. Acesso em: 20 jul. 
2008.

LAMARCHE, H. (Coord.). A agricultura familiar: comparação internacional. Campinas: Unicamp, 1993. v. 1: Uma realidade multiforme.

LOUREZANI, A.E.B.S.; SILVA, A.L. Um estudo de competitividade dos diferentes canais de distribuição de hortaliças. GEPAI - Grupo de Estudos e Pesquisas Agroindustriais. São Paulo: Universidade Federal de São Carlos, UFScar, 2004.

MARTINELLI, D.P.; JOYAL, A. Desenvolvimento local e o papel das pequenas e médias empresas. Barueri, SP: Manole, 2004. 314 p.

MARTINS, S.R. O. Desenvolvimento local: questões conceituais e metodológicas. Interações - Revista Internacional de Desenvolvimento Local, Campo Grande, MS, v. 1, n. 1, p. 63-76, set. 2002.

MMA - Ministério do Meio Ambiente. Município de Capanema. Disponível em: <http://www.ibama.gov.br/ parna_iguacu/index.php?id_menu=111>. Acesso em: 10 maio 2008.

MIOR, L.C. Agricultores familiares, agroindústrias e redes de desenvolvimento rural. Chapecó: Argos, 2005. 338 p.

MTE - Ministério do Trabalho e Emprego. Plano Territorial de Qualificação do Estado do Paraná. PlanTeQ/ PR 2004-2007. Curitiba, 2004. Disponível em: $<$ httpwww.sine.pr.gov.brsetpcqpplanteq_1_2.pdf>. Acesso em: 22 jun. 2008.
PERONDI, M.A.; KIYOTA, N. Gestão na agroindústria familiar de pequeno porte de cana-de-açúcar. In: MORAES, M.A.F.D.;SHIKIDA, P.F.A. (Orgs.). Agroindústria canavieira no Brasil: evolução, desenvolvimento e desafios. São Paulo: Atlas, 2002. p. 354-367.

PREFEITURA MUNICIPAL DE CAPANEMA. Diagnóstico Local do Município de Capanema. 2007. Disponível em: <httpportal.saude.gov.brportal arquivospdfDiagnostico__Local_Capanema-PR.pdf $>$. Acesso em: 20 jun. 2008.

PREZOTTO, L.L. A agroindústria rural de pequeno porte e o desenvolvimento local/regional. In: CONFERÊNCIA INTERNACIONAL DE DESENVOLVIMENTO SUSTENTÁVEL E AGROINDÚSTRIA, 2000. Anais... Lajeado/RS, 2000.

SANTOS, M.; SILVEIRA, M.L. O Brasil: território e sociedade no início do século XXI. 8. ed. Rio de Janeiro: Record, 2005.

SCHNEIDER, S. Teoria social, agricultura familiar e pluriatividade. Revista Brasileira de Ciências Sociais, v. 18, n. 51, p. 99-121, fev. 2003.

SHIKIDA, P.F.A.; SOUZA, E.C.de; DAHMER, V.de S.; Agroindústria canavieira e desenvolvimento local: o caso da Usina Usaciga no município de Cidade GaúchaPR. Revista de Economia e Agronegócio, Viçosa (MG), v. 6, n. 1, p. 133-155, jan./abr. 2008.

VEIGA, J.E. Agricultura familiar e sustentabilidade. Cadernos de Ciência e Tecnologia, EMBRAPA, v. 13, n. 3, p. 383-404, set./dez. 1996. 